\title{
ENHANCEMENT OF OXYGEN TRANSFER THROUGH MEMBRANES IN BIOPROCESSES
}

\author{
Péter KomÁromy ${ }^{* 1}$, KatAlin Bélafi-BaKó ${ }^{1}$, Éva HüLber-BeyeR ${ }^{1}$, AND NÁNDOR \\ NEMESTÓTHY ${ }^{1}$ \\ ${ }^{1}$ Research Institute on Bioengineering, Membrane Technology and Energetics, University of Pannonia, \\ Egyetem u. 10, Veszprém, 8200, HUNGARY
}

\begin{abstract}
In several aerobic bioprocesses, it is extremely important to provide a sufficient amount of oxygen, which is a difficult task since the solubility of oxygen in aqueous systems, namely in water, is low. Thus oxygen transfer techniques should be designed, built, studied and operated very carefully in biosystems. Moreover, in certain cases, special techniques, e.g. involving membranes, must be applied. In this paper, three different bioprocesses are presented where oxygen was supplied by membrane aeration: wastewater treatment by microbial consortia (i), itaconic acid fermentation by a single microorganism (ii) and an oxidative enzyme catalytic process for the elimination of glucose (iii).
\end{abstract}

Keywords: biotechnology, aerobic microbes, silicone membrane, enzyme

\section{Introduction}

At the dawn of applied and industrial biotechnology, the use of engineering tools to establish reliable bioprocesses for manufacturing certain bioproducts was inevitable [14]. For the effective production of acetic acid, ethanol and later citric acid, etc. by biological processes, the technical skills and experience of chemical engineering were used together with microbiological knowledge and practices to establish bioengineering and bioprocess engineering.

Several bioprocesses require oxygen for various purposes, e.g., respiration, certain energy-producing metabolic pathways, direct oxidation, the oxidative degradation of some substrates, etc. [1-3]. Oxygen is usually supplied by surface aeration, bubble aeration (sparging), by entering oxygen or air directly, aeration combined with agitation or in airlift bioreactors. Regardless, oxygen is always transported from a gas stream to an unsaturated liquid [5]. The steps of this pathway are as follows and are outlined in Fig. 1:

- from the inside of the bubble to the surface (gas side) (1);

- through the boundary layer of the bubble (liquid side) (2);

- from the surface to the bulk liquid (broth) (3);

- from the bulk liquid to the liquid film layer of the cell (4);

\footnotetext{
*Correspondence: komaromy.peter@mk.uni-pannon.hu
}

- into the microbial cells (through the liquid film layer) (5).

Moreover, it is important to take into consideration that the oxygen demand changes as a function of time and according to the characteristics of the particular form of cell.

In the liquid film layers, the transfer occurs by diffusion, while in the bulk phase, it always takes place via convective transport (which can be enhanced by mixing). The rate-limiting step is diffusion through the boundary film layer of the bubble on the liquid side, which is highly influenced by its surface area.

On the other hand, membranes have been used in bioprocesses for an extensive period of time [6-9]. However, firstly they were exclusively applied for separations [6-8]. Membranes that are distinctly selective towards certain gases were used to develop gas separation techniques. Some of these membranes are permeable to oxygen molecules in the gaseous phase, therefore, it was a breakthrough to apply them for oxygen transfer into the aqueous (liquid) phase [9]. One of the most important benefits of this kind of aeration is the amplified surface area between the gaseous (air or pure oxygen) and liquid phases.

In this work, three different bioprocesses are presented where oxygen was supplied by membrane aeration:

- wastewater treatment by microbial consortia;

- fermentation by a single microorganism (under sterile conditions) for the manufacture of an organic 


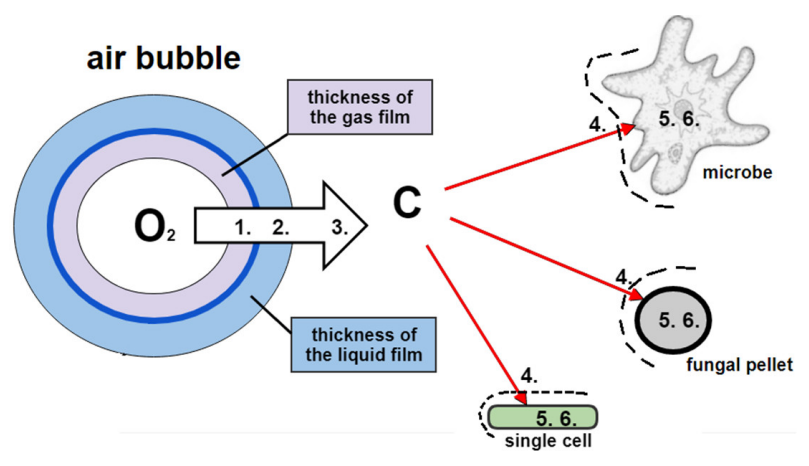

Figure 1: The pathway of oxygen transfer.

acid;

- an enzymatic oxidation for the elimination of glucose.

\section{Membrane-aerated bioreactors for the treatment of wastewater}

The combination of membrane technology with the biological treatment of municipal and industrial wastewater has been investigated and applied for an extensive period of time. Coupling the two systems resulted in a special, new type of reactor called a membrane bioreactor (MBR). The roles of membranes in these biological systems include:

- separation of solids;

- aeration;

- extraction of special pollutants.

The supply of oxygen to microbes through a membrane is carried out by a membrane-aerated bioreactor (MABR). This type of bioreactor was developed in 1978 and has been studied ever since. The membrane itself has to exhibit a high degree of oxygen permeability. Among gas-separation membranes, silicone (polydimethylsiloxane) was used for oxygen enrichment (from air), thus seemed suitable for this purpose. Oxygen mass transfer through a silicone membrane was closely examined [9] and it was determined that the membrane aeration system was approximately 7 times more effective in terms of oxygen supply than the standard activated sludge process, hence it was experimentally proven to have strong potential.

In different wastewater treatment processes, various gas-permeable membranes were tested with regard to oxygen supply systems [11-14]:

- polyethylene;

- ethyl cellulose;

- polystyrene;

- polytetrafluorethylene;

- polypropylene;<smiles>C=C(CC(=O)O)C(=O)O</smiles>

Figure 2: Chemical structure of itaconic acid.

- polyetherimide;

- silicone.

In terms of configuration, mainly hollow fibre modules were successfully applied (though plate-and-frame modules can also be used). The membrane was placed into the liquid waste (submerged system) and oxygen from the air was pumped inside the lumen. Oxygen was transferred by diffusion through the membrane directly into the biomass that formed on the shell side of the membrane. The main benefits of the system are that no bubbles are formed and bubble-to-liquid transfer (diffusion limitation) could be avoided.

The membrane aerated bioreactor system is continuously being developed and finally a truly reliable, robust and viable system was established [15], namely the ZeeLung system. It consists of a silicone, non-porous polymer membrane with an extremely small outer diameter $(50-70 \mu \mathrm{m})$ and wall thickness $(5-20 \mu \mathrm{m})$. Thus the module has a very high surface area, low packing density and an efficient rate of oxygen transfer can be maintained under low pressure. The new system (technology) resulted in an energy efficiency four times greater than that of conventional bubble aeration.

By comparing membrane aeration with traditional bubble aeration, another benefit can be recognized. A homogeneous oxygen concentration can be achieved throughout the reactor by pumping through air or oxygen bubbles. When membrane aeration is applied, it is possible to establish different oxygen levels within the reactor: several zones with various oxygen levels (as required for certain biological processes) can be created.

\section{Fermentation of itaconic acid}

Itaconic acid is an unsaturated five-carbon dicarboxylic acid that is considered to be an important platform molecule of high potential (bio-based building block) (Fig. 2). It was specified by the United States Department of Energy as one of the 12 most promising chemicals obtained from biomass.

Itaconic acid is mainly produced biologically by filamentous fungi, e.g. Aspergillus terreus [16-20].

The fermentation of itaconic acid is a quite sensitive process that requires a high initial substrate concentration of glucose, precise control of operational parameters (e.g. $\mathrm{pH}$, temperature, presence/deficiency of certain ions, etc.) and a high oxygen level since a high level of oxygen tension in the fermenter enhances the formation of itaconic 
acid. A sufficient oxygen supply can be ensured by increasing the mixing rate, however, filamentous fungi are generally very sensitive to high shear rates. Moreover, intensive foaming may result which must be avoided. As the fermentation progresses, ever more biomass and protein is produced in the broth, hence these phenomena may occur more acutely. In addition, the oxygen demand continuously increases.

Oxygen can be supplied by conventional techniques, e.g. airlift bioreactors, air bubbling equipped with propeller agitators, etc. For example, an airlift bioreactor was combined with a modified draft tube to achieve a high $(2,4301 / \mathrm{h})$ volumetric oxygen transfer coefficient [21].

In our laboratory, membrane aeration was applied by pumping $600 \mathrm{l} / \mathrm{h}$ of air at a pressure of 1.1 bar into the broth by using a special PermSelect hydrofluoric acid (HF) silicone membrane which was immersed into the fermenter. This membrane was originally an oxygenselective gas separation membrane, consisting of 10 thousand fibres $(O D=150 \mu \mathrm{m})$ with a surface area of $1 \mathrm{~m}^{2}$. Since oxygen permeated faster than other compounds, it resulted in a high oxygen supply. Our successful experiments have proven that by applying membrane aeration, enhanced oxygen transport and a higher yield of itaconic acid are achieved.

\section{Enzymatic removal of glucose}

In the food industry, some processes require the removal of glucose [22]. For example, in the manufacture of powdered egg white, the reaction between glucose and protein results in the Maillard browning reaction during the spray-drying step, leading to an undesirable brown discolouration and poor quality [23]. Another example is the manufacture of low-calorie, low-alcohol beverages from fruit juices [24]. The content of fermentable sugar can be reduced significantly by converting it into other compounds which cannot be metabolised into ethanol (less alcohol forms).

Glucose (or dextrose, its chemical name is Dglucopyranose) is the most abundant monosaccharide, a six-carbon sugar (hexose) with five hydroxyl groups. Its name is derived from the Greek word "glukos" which means "sweet".

The extraction of glucose from a mixture containing compounds of similar molecular size is generally difficult as well-known separation techniques are unsuitable [6-8]. Therefore, a special enzymatic method has been developed where glucose is oxidised. The enzyme catalysing the reaction is called glucose oxidase (GOD), E.C. 1.1.3.4 [25,26]. During the reaction, glucose is converted into D-glucono-1,5-lactone, which spontaneously hydrolyses non-enzymatically into gluconic acid:

$$
\beta-\mathrm{D}-\text { glucose }+\mathrm{O}_{2} \longrightarrow \mathrm{D}-\text { gluconic acid }+\mathrm{H}_{2} \mathrm{O}_{2}
$$

The reaction uses oxygen and releases hydrogen peroxide as a by-product, which has a strong inactivation effect on GOD itself, therefore, it must be eliminated from the mixture. $\mathrm{H}_{2} \mathrm{O}_{2}$ can be converted into water and molecular oxygen by another enzyme called catalase, E.C. 1.11.1.6.:

$$
\mathrm{H}_{2} \mathrm{O}_{2} \longrightarrow \mathrm{H}_{2} \mathrm{O}+\frac{1}{2} \mathrm{O}_{2}
$$

The two enzymes can be applied together, such an enzyme mixture can be manufactured by various moulds, e.g., species of Aspergillus.

For the successful operation of the enzyme, a sufficient amount of oxygen should be supplied. In the case of the production of powdered egg white, traditional aeration methods (e.g. bubble aeration) cause a high degree of foaming, thus another technique should be implemented. In our laboratory, membrane aeration was studied and applied [27]. The enzyme complex was immobilized on a resin and a packed column reactor set up for the reaction. Then a perforated silicone tube membrane was placed inside the bioreactor in a spiral configuration to provide oxygen directly to the site of the enzymatic oxidation reaction.

\section{Conclusion}

In summary, three different bioprocesses were presented in this paper where oxygen was supplied using a special method, namely membrane aeration. Firstly, the treatment of wastewater by microbial consortia (i), secondly, the fermentation of itaconic acid by a single microorganism (ii) and finally, an oxidative enzymatic process (iii) for the elimination of glucose were examined in detail.

\section{Acknowledgement}

The research work was supported by the National Research, Development and Innovation Fund Project K 119940 entitled "Study on electrochemical effects on bioproduct separation by electrodialysis" and project EFOP3.6.1-16-2016-00016.

\section{REFERENCES}

[1] Doran, P. M.: Bioprocess Engineering Principles (Academic Press, Waltham, Massachusetts, USA) 2013, ISBN: 978-00-8091-770-2

[2] Ratledge, C.; Kristiansen, B. (Eds.): Basic Biotechnology (Cambridge University Press, Cambridge, UK) 2006, ISBN: 978-05-2154-958-5

[3] Bailey, J. E.; Ollis, D. F.: Biochemical Engineering Fundamentals (McGraw Hill, New York, USA) 1986, ISBN: 978-00-7003-212-5

[4] Atkinson, B.; Mavituna, F.: Biochemical Engineering and Biotechnology Handbook (The Nature Press, London, UK) 1983, ISBN: 0-333-33274-1

[5] Komaromy, P., Sisak, Cs.: Investigation of gasliquid oxygen transport in three-phase bioreactor, Hung. J. Ind. Chem. 1994, 22(2), 147-151 
[6] Mulder, M.: Basic principles of membrane technology (Kluwer Academic Publisher, Dordrecht, The Netherlands) 1996, ISBN: 978-94-009-1766-8

[7] Baker, R. W.: Membrane Technology and Applications (Wiley, New York, USA) 2012, ISBN: 978-04708-5445-7

[8] van Reis, R.; Zydney, A.: Membrane separations in biotechnology, Current Opin. Biotechnology 2001, 12(2) 208-211 DOI: 10.1016/S0958-1669(00)00201-9

[9] Charcosset, C.: Membrane Processes in Biotechnology and Pharmaceutics (Elsevier, Amsterdam, The Netherlands) 2012, ISBN: 978-04-445-6334-7

[10] Hirasa, O.; Ichijo, H.; Yamauchi, A.: Oxygen transfer from silicone hollow fiber membrane to water, J. Ferm. Bioeng. 1991, 71(3), 206-207 DOI: 10.1016/0922-338X(91)90113-U

[11] Irvine, R.; Sikdar, S. H.: Fundamentals and Application of Bioremediation: Principles (CRC Press, New York, USA) 1997, ISBN: 978-15-667-6308-0

[12] Stephenson, T.; Brindle, K.; Judd, S.; Jefferson, B.: Membrane Bioreactors for Wastewater Treatment (IWA Publishing, London, UK) 2000, ISBN: 978-19002-2207-5

[13] Brindle, K.; Stephenson, T.: The application of membrane biological reactors for the treatment of wastewaters, Biotechnol. Bioeng. 1996, 49(6), 601-610 DOI: 10.1002/(SICI) 10970290(19960320)49:6<601::AID-BIT1>3.0.CO;2-S

[14] Brepols, C.: Operating large scale membrane bioreactors for municipal wastewater treatment (IWA Publishing, London, UK) 2010, ISBN: 978-18-4339305-4

[15] Stricker, A. E.; Lossing, H.; Gibson, J. H.; Hong, Y.; Urbanic, J. C.: Pilot scale testing of a new configuration of the membrane aerated biofilm reactor (MABR) to treat high-strength industrial sewage, Water Env. Res. 2011, 83(1), 3-14 DOI: 10.2175/106143009X12487095236991

[16] Jang, Y. S.; Kim, B.; Shin, J. H.; Choi, Y. J.; Song, C. W.; Lee, J., Park, H. G.; Lee, S. Y.: Bio-based production of C2-C6 platform chemicals, Biotechnol. Bioeng. 2012, 109(10), 2437-2459 DOI: 10.1002/bit.24599

[17] da Cruz, J. C.; Camporese Servulo, E. F.; de Castro, A. M.: Microbial production of itaconic acid, in Microbial production of food ingredients and additives in Handbook of Food Bioengineering Holban, A. M., Grumuzescu, A.M. (Eds.) (Academic Press, Elsevier, Amsterdam, The Netherlands) 2017, pp. 291-316, DOI: 10.1016/B978-0-12-811520-6.00010-6
[18] Varga, V.; Bélafi-Bakó, K.; Vozik, D.; Nemestóthy, N.: Recovery of itaconic acid by electrodialysis, Hung. J. Ind. Chem. 2018, 46(2), 43-46 DOI: 10.1515/hjic-2018-0017

[19] Karaffa, L.; Diaz, R.; Papp, B.; Fekete, E.; Sandor, E.; Kubicek, C. P.: A deficiency of manganese ions in the presence of high sugar concentrations is the critical parameter for achieving high yields of itaconic acid by Aspergillus terreus, Appl. Microbiol. Biotechnol. 2015, 99, 7937-7944 DOI: 10.1007/s00253015-6735-6

[20] Komáromy, P.; Bakonyi, P.; Kucska, A.; Tóth, G.; Gubicza, L.; Bélafi-Bakó, K.; Nemestóthy, N.: Optimized $\mathrm{pH}$ and its control strategy lead to enhanced itaconic acid fermentation by Aspergillus terreus on glucose substrate, Fermentation, 2019, 5(2), 31-39 DOI: 10.3390/fermentation5020031

[21] Okabe, M.; Ohta, N.; Park, Y. S.: Itaconic acid production in an air-lift bioreactor using a modified draft tube, J. Ferm. Bioeng. 1993, 76(2), 117-122 DOI: 10.1016/0922-338X(93)90067-I

[22] Varzakas, T.; Tzia, C.: Food Engineering Handbook, Food Process Engineering (CRC Press, Amsterdam, The Netherlands) 2014, ISBN: 978-14-6658226-2

[23] Kilara, A.; Shahani, K. M.: Removal of glucose from eggs: A review, J. Milk Food Technol. 1973, 36(10), 509-514 DOI: 10.4315/0022-2747-36.10.509

[24] Heresztyn, T.: Conversion of glucose to gluconic acid by glucose oxidase enzyme in Muscat Gordo juice, The Australian Grapegrower and Winemaker, 1987, 4, 25-27

[25] Sisak, Cs.; Csanádi, Z.; Rónay, E.; Szajáni, B.: Elimination of glucose in egg white using immobilized glucose oxidase, Enzyme $\mathrm{Mi}$ crob. Technol., 2006, 39(5), 1002-1007 DOI: 10.1016/j.enzmictec.2006.02.010

[26] Pečar, D.; Vasić-Rački, Đ.; Presečki, V.: Immobilization of glucose oxidase on Eupergit C: Impact of aeration, kinetic and operational stability studies of free and immobilized enzyme, Chem. Biochem. Eng. Q. 2018, 32(4), 511-522 DOI: 10.15255/CABEQ.2018.1391

[27] Bélafi-Bakó, K.: Possibilities for removal of glucose from various foodstuffs and food bioprocesses, in New Topics in Food Engineering, Siegler, B.C. (Ed.) (Nova Science Publishers, New York, USA) 2010, pp. 289-299 ISBN: 978-161209599-8 